\title{
GeoGebra e Impressão 3D: desenvolvendo o Pensamento Geométrico Espacial
}

\author{
Larissa Weyh Monzon ${ }^{1}$, Marcus Vinicius de Azevedo Basso ${ }^{1}$ \\ ${ }^{1}$ Programa de Pós-Graduação em Informática na Educação (PPGIE) \\ Universidade Federal do Rio Grande do Sul (UFRGS) \\ Porto Alegre - RS - Brasil \\ \{larissamonzon@gmail.com, mbasso@ufrgs.br
}

\begin{abstract}
The use of digital Technologies can provide situations where students are active in their knowledge building process. However, it's necessary that such situations be created aiming the development of new math thoughts and skills. This article presents a problem situation proposal where the students were challenged to design a three-dimensional object using the GeoGebra software and later prove and analyse the results with the $3 D$ printing. Given this, they had the opportunity to generalize different geometric concepts already assimilated and reorganize them into a higher cognitive level.
\end{abstract}

Resumo. $O$ uso de tecnologias digitais pode propiciar situações onde os estudantes estão ativos em seu processo de construção de conhecimentos. Porém, é necessário que tais situações sejam criadas almejando o desenvolvimento de novos pensamentos e habilidades matemáticas. Este artigo, apresenta uma proposta de situação problema onde os alunos foram desafiados a projetar um objeto tridimensional utilizando o software GeoGebra e posteriormente comprovar e analisar os seus resultados com a Impressão 3D. Diante disso, tiveram a oportunidade de generalizar diferentes conceitos geométricos já assimilados e reorganizá-los em um patamar superior cognitvo.

\section{Introdução}

As tecnologias estão colocando à disposição dos estudantes mecanismos que favorecem e exigem a construção de conceitos e o pensamento matemático. Os computadores estão possibilitando uma nova abordagem da matemática a ser construída, na qual novas habilidades podem ser desenvolvidas. Para Laborde e outros (2006) as possibilidades das tecnologias está modificando as estratégias dos alunos e, assim, sua forma de pensar e novas formas de conceituar ideias matemáticas.

Pesquisadores [BASSO e NOTARE 2015; KAPUT, HEGEDUS e LESH 2007] estão sugerindo o uso dos softwares para transferir cálculos e operações, ou seja, transferir habilidades operacionais para as máquinas. Mas, diante disso, não se sabe o que fazer sobre as novas habilidades que esse fato pode proporcionar ou exigir. Para Kaput, Hegedus e Lesh (2007) o impacto das tecnologias na educação é a evolução em novas formas de ensinar, melhor aprendizado, novo currículo e habilidades para resolver problemas. 
VIII Congresso Brasileiro de Informática na Educação (CBIE 2019)

Anais do XXV Workshop de Informática na Escola (WIE 2019)

Resolver um problema é explorar seus conhecimentos já adquiridos e criar estratégias para resolver algo novo, assim, conjecturando novos conceitos e concluindo ideias. Para isso, os estudantes deverão compreender os dados, tomar decisões para resolvê-lo, estabelecer relações e tirar conclusões. Essa oportunidade de tais explorações proporcionam aos alunos o ato de aprender e estimular seus processos de pensamento superior, tornando-os assim, indivíduos intelectuais competentes [ZUFFI e ONUCHIC 2007].

Diante desses apontamentos, apresenta-se para este artigo a seguinte questão: Como as tecnologias digitais, construindo e manipulando objetos espaciais em software de geometria dinâmica e com a impressão 3D, podem proporcionar experiências para contribuir para o desenvolvimento do pensamento geométrico espacial através de uma situação problema?

Essa questão faz parte de uma pesquisa mais ampla de tese de doutorado, na qual os pesquisadores buscaram, em uma revisão sistemática, o panorama atual de pesquisas que envolvem o uso das tecnologias para o desenvolvimento do pensamento geométrico espacial no ensino básico. Nesta revisão, verificou-se uma carência de pesquisas divulgadas no cenário de publicações internacionais que contemplam e visam o desenvolvimento do pensamento geométrico utilizando alguma tecnologia em estudantes do ensino básico [MONZON e BASSO 2018].

Para analisar a questão anteriormente levantada, apresenta-se neste artigo as seções 2 e 3, onde encontram-se os aportes teóricos que proporcionaram a contrução de uma situação problema que utilizasse software de geometria dinâmica e a impressão 3D. Na seção 4 é exposto a aplicação desse problema, como também as análises de como essa situação problema impactou no pensamento geométrico de estudantes do ensino médio baseadas também na teoria apresentada. Por fim, na seção 5, tem-se as considerações finais.

\section{Geometria dinâmica: software GeoGebra}

Segundo Kaput, Hegedus e Lesh (2007) a geometria dinâmica surgiu por volta de 1980, mas continua impactando pesquisadores, alunos e professores sobre como esses ambientes permitem que os alunos construam seu próprio aprendizado.

Os primeiros softwares de geometria dinâmica chegaram aproveitando o progresso das interfaces gráficas dos computadores, com o principal objetivo de fornecer um conjunto de imagens representando um conjunto de conceitos geométricos, assim, podendo perceber os aspectos gerais de um elemento estático através de uma variedade desses elementos. A teoria do construtivismo geralmente esteve ligada às pesquisas com esses softwares, destacando que a aprendizagem é construída pelo próprio estudante, havendo uma reconstrução da geometria [LABORDE et. al 2006].

Com esses softwares foi possível tornar real objetos matemáticos na tela do computador com a possibilidade de manipulação e alteração de suas propriedades, surgindo uma nova forma de pensar e fazer matemática [NOTARE e BASSO 2016]. Os ambientes de geometria dinâmica possuem uma natureza exploratória, sendo considerados favoráveis à aprendizagem, pois exigem dos alunos ações para atingir certos objetivos, conforme a aplicação realizada no software. Explorando essas 
VIII Congresso Brasileiro de Informática na Educação (CBIE 2019)

Anais do XXV Workshop de Informática na Escola (WIE 2019)

construções na tela, os alunos conseguem atingir características do objeto geométrico, esse processo demonstra que tais ferramentas se tornam extensões do próprio pensamento do aluno [LABORDE et. al 2006; NOTARE e BASSO 2016].

Segundo Notare e Basso (2016) há um crescimento na utilização desses softwares para ensinar geometria, citam o uso do software GeoGebra, porém afirmam que o uso da versão 3D do mesmo continua escasso. Especificamente em relação ao GeoGebra 3D, software escolhido para esta proposta, hoje ele se classifica como software de matemática dinâmica, pois apresenta não só recursos de geometria, mas também outras áreas da matemática como álgebra e estatística.

As impressoras 3D fazem uso de softwares de impressão que exigem arquivos com extensão, na maioria, STL (stereolithography). No andamento desta pesquisa, os desenvolvedores do GeoGebra começaram a testar uma versão com configurações compatíveis com as impressoras 3D, ou seja, a possibilidade de salvar o arquivo construído no GeoGebra em extensão STL. Assim, para os estudos desta proposta, os autores da pesquisa tiveram acesso e fizeram uso da versão "teste" do programa e, atualmente, a versão do GeoGebra compatível com o formato STL está disponível para os usuários.

\section{Impressão 3D}

Segundo Laborde e outros (2006), é importante a transferência do ambiente do computador para o mundo fora do computador. Acrescenta-se que os softwares de geometria dinâmica podem proporcionar experiências positivas para trabalhar com conceitos de geometria, mas não se pode esquecer uma das caraterísticas destas tecnologias: a visualização bidimensional, tanto da tela do computador quanto da operação com o mouse. Isso é um problema para representar e interagir com objetos geométricos tridimensionais [JONES, MACKRELL e STEVENSON 2010].

Em relação a isso, esta proposta pretende verificar as possibilidades de tornar os objetos teóricos virtuais, ricos em propriedades e conceitos matemáticos e criados no ambiente de geometria dinâmica, em objetos físicos, que os alunos, os próprios criadores desses objetos virtuais, poderão tocar através da impressão 3D.

Segundo Canessa (2013), a impressão 3D foi desenvolvida na década de 1980 para a área industrial, pois era de alto custo. A expansão dessa tecnologia se deve a nova tecnologia desenvolvida, a impressão de objetos camada por camada por plástico derretido (FDM- Fused Deposition Modeling), o código aberto e o compartilhamento gratuito de arquivos pela internet. Nos últimos anos o preço das impressoras 3D caiu mais de 10 vezes [HULEIHIL, 2017].

Segundo Bicer e outros (2017), a modelagem com software 3D para projetar e imprimir produtos pode melhorar as habilidades de visualização espacial, criatividade e habilidades de resolução de problemas dos alunos, também afirma que pesquisas sobre o efeito desse uso permanece limitado. Salienta que o uso dos softwares 3D na sala de aula ganhou um forte aliado com as impressoras. Já para Huleihil (2017) esse tipo de impressão desenvolve diferentes habilidades, incluindo de matemática, geometria, resolução de problemas, imaginação, inovação, design, ciência dos materiais e processos 
VIII Congresso Brasileiro de Informática na Educação (CBIE 2019)

Anais do XXV Workshop de Informática na Escola (WIE 2019)

de produção. Para ele, colocá-los juntos é desafiante, ao mesmo tempo motivador para os estudantes.

\section{A experiência didática e as análises}

A experiência aqui apresentada faz parte de uma tese de doutorado que trata de uma investigação com abordagem qualitativa com o objetivo descritivo em uma modalidade de estudo de casos múltiplos, que está unindo as características estudadas da geometria dinâmica com a impressão 3D.

A aplicação da situação proposta ocorreu durante uma disciplina eletiva no turno inverso dos estudantes do ensino médio, em uma escola pública de Porto Alegre. A disciplina foi realizada durante o segundo semestre letivo de 2018, uma vez por semana em duas horas/aula. Convidados para participar da disciplina, doze estudantes aceitaram o convite e ficaram envolvidos em atividades explorando conceitos e habilidades geométricas espaciais fazendo uso do software GeoGebra e da impressão 3D. Cada atividade proposta foi disponibilizada via ambiente Google Sala de Aula, no qual é possível anexar arquivos, endereços eletrônicos, criar diferentes questionamentos e uma interação constante entre pesquisadores e participantes através de mensagens e comentários

O software utilizado na experiência foi o GeoGebra, previamente instalado nas máquinas de um dos ambientes informatizados da escola. O modelo de impressora 3D foi a Stella 2.0, nacional, com um suporte técnico online muito satisfatório, possui como dimensão de impressão 20x20x20cm com uma velocidade máxima de $90 \mathrm{~mm} / \mathrm{s}$, imprime em PLA, PETG, TPU (Flex), Nylon (Poliamida), compostos como o Woodfill, Bronzefill, fosforescente.

\subsection{A Situação Problema}

Uma das atividades utilizada na pesquisa da tese foi uma situação problema dividida em duas partes, a primeira está apresentada na Figura 1.

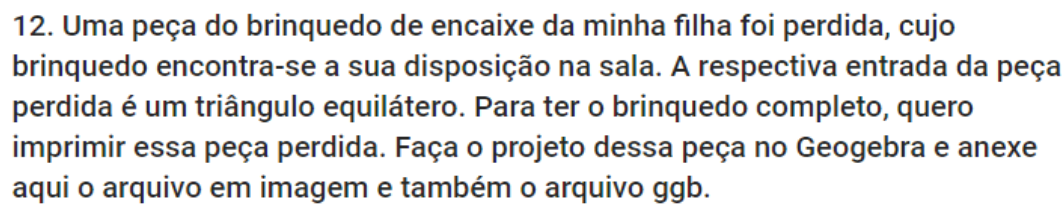

Figura 1. Primeira parte da situação problema

O brinquedo o qual se trata na situação estava a disposição dos participantes no momento da experiência, a Figura 2 traz a imagem do brinquedo mencionado.

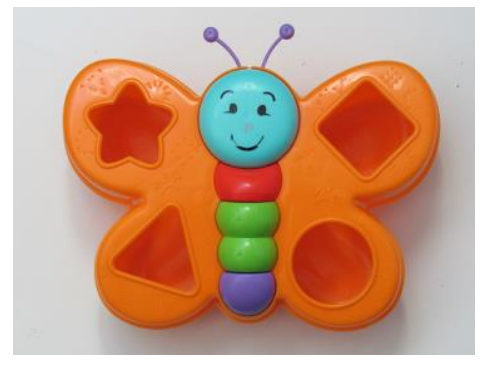

Figura 2. Brinquedo utilizado no problema 
VIII Congresso Brasileiro de Informática na Educação (CBIE 2019)

Anais do XXV Workshop de Informática na Escola (WIE 2019)

Com a pretensão de entender o pensamento dos participantes perante a resolução do problema apresentado, foram elaboradas o que foi chamado de Questões Auxiliares, as quais foram baseadas nas teorias apresentadas nas seções anteriores e tiveram a pretensão de ajudar nas análises:

- Como você construiu o triângulo equilátero? Quais estratégias do software você utilizou para que ficasse com os três lados congruentes?

- Essa peça que você construiu vai entrar com facilidade no orifício do brinquedo? Será um desafio para minha filha ou será muito fácil?

- A peça pode ser encaixada de várias posições?

Hipóteses: verificar que para ser um triângulo equilátero deverá partir de suas propriedades, constatar que o tamanho da peça deve ser levemente menor do que a entrada da peça no brinquedo para que seja possível mas também que não facilite a brincadeira.

A seguir, na Figura 3, apresenta-se a segunda parte do problema, este relacionado à utilização da impressora $3 \mathrm{D}$.

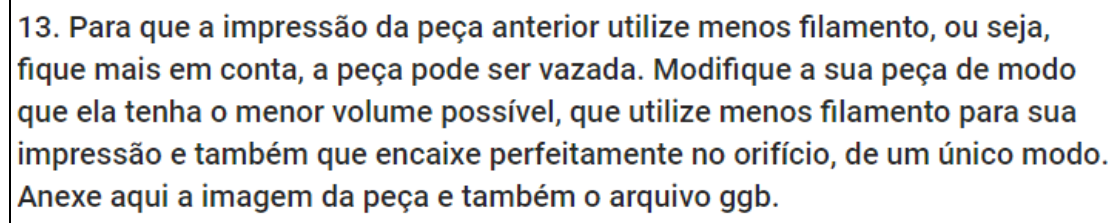

\section{Figura 3. Segunda parte da situação problema}

Questões Auxiliares:

- Qual estratégia utilizada para construir a peça vazada?

Hipótese: construir um sólido dentro do outro e ainda, pode ser feita sem nenhuma das bases para que tenha custo baixo.

- Essa é a forma com menos volume possível?

Hipótese: que o aluno reflita sobre sua construção e verifique se pode haver outras maneiras de fazê-la.

- A impressora funciona com a impressão em camadas, ou seja, uma camada sobre a outra, será possível imprimir sua peça?

Hipótese: Se os alunos construírem a peça com uma base fechada, essa base deve ficar na parte inferior no momento da impressão, pois se ficar na superior não haverá sustentação.

- No momento de mandar imprimir, a sua peça possui uma posição para que seja possível a impressão?

Hipótese: Se os alunos construírem a peça com uma base fechada, essa base deve ficar na parte inferior no momento da impressão, pois se ficar na superior não haverá sustentação.

Mesmo os pesquisadores terem hipóteses para cada situação, estas serviram somente como um apoio no momento da construção do problema e das Questões Auxiliares, o objetivo aqui não é chegar em um resultado único e certo. Os pesquisadores tem consciência que a resolução de problemas acarreta muito mais do que 
VIII Congresso Brasileiro de Informática na Educação (CBIE 2019)

Anais do XXV Workshop de Informática na Escola (WIE 2019)

um resultado premeditado. A seguir, apresenta-se as análises da experiência, onde mostra-se justamente o surgimento de diferentes resultados.

\subsection{As análises}

Além das respostas a essas Questões Auxiliares no Google Sala de Aula, os pesquisadores tiveram à disposição para suas análises o arquivo com a construção da peça (exemplo Figura 4), no qual é possível visualizar o passo a passo da construção (recurso do GeoGebra), as anotações de um dos pesquisadores sobre o comportamento, dúvidas e apontamentos que os participantes fizeram no momento da atividade, a peça impressa de cada participante e também dois dos alunos escolheram essas atividades para apresentar ao grande grupo, na referida apresentação a pesquisadora realizou outros questionamentos, tal apresentação está gravada em video.

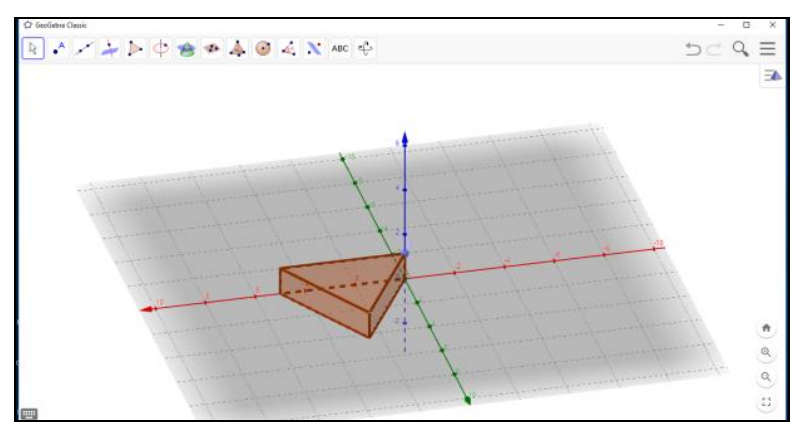

Figura 4. Exemplo da construção de um participante no GeoGebra

Todos os participantes perceberam que se tratava de um sólido triangular regular e utilizaram diferentes estratégias de construção para chegar no triângulo equilátero da base. Por exemplo, Picasso (os nomes dos participantes aqui utilizados são fictícios) descreveu sua estratégia da seguinte forma: "primeiro fiz dois pontos que possuem $5 \mathrm{~cm}$ de distância entre eles depois escolhi um ponto médio para descobrir a ponta então tracejei o terceiro ponto baseado no ponto médio depois criei uma reta perpendicular em um dos pontos logo em seguida o triângulo estava pronto só faltava ajustar a altura depois de ajustar a altura o triângulo estava feito". Nota-se que ele estabeleceu relações, significados com esquemas já construídos de diferentes conceitos de geometria, quais ele não retirou do objeto observado no brinquedo, mas sim, de esquemas sobre o triângulo equilátero interiorizadas, com as generalizações dessas propriedades conseguiu construir o triângulo, ou seja, passou para um patamar cognitive superior. $\mathrm{O}$ participante Faraday utilizou outros conhecimentos assimilados anteriormente de que o triângulo equilátero possui os três ângulos internos medindo $60^{\circ}$, ou seja, para construí-lo utilizou esse conhecimento para chegar no triângulo pretendido: "Utilizei a ferramenta de medida de ângulo para todos os lados fiquem iguais".

$\mathrm{Na}$ apresentação realizada por um dos colegas, notamos outra generalização:

Pesquisadora: ... alguém quer explicar como fez?

Monet: Distância entre dois pontos.

Pesquisadora: Como assim, Monet?

Monet: Eu fiz o cálculo numa folha pra conseguir ter os três lados iguais.

Entendeu? Primeiro eu criei uma aresta, tá?

Pesquisadora: Tá. 
VIII Congresso Brasileiro de Informática na Educação (CBIE 2019)

Anais do XXV Workshop de Informática na Escola (WIE 2019)

Monet: Depois, no triângulo eu precisava só mais um ponto para ligar os segmentos, dai eu calculei a distância de dois pontos igual a 5.

Toda vez que é necessário utilizar uma das estruturas cognitivas já formadas e reorganizá-las para utilizar de uma outra forma, fazer uma generalização, se está passando de um patamar inferior cognitivo para um superior, ou seja, se está evoluindo, desenvolvendo o pensamento. "O GeoGebra forneceu recursos que permitiram que os alunos criassem construções geométricas mais precisas e conectassem essa ferramenta cuidadosamente com seu aprendizado matemático" [LIEBAN et al. 2018, tradução dos autores].

O problema proposto exigia que os alunos observassem as características geométricas do objeto, ou seja, as características visíveis, mas também precisavam considerar o objetivo do brinquedo, ou seja, precisavam refletir sobre o funcionamento inobservável do objeto. Para isso, as Questões Auxiliares foram fundamentais.

Em muitos momentos na resolução de um problema, os alunos não levaram em consideração todas as implicações necessárias, para algumas delas foi necessário a intervenção de um mediador, papel este realizado por um dos pesquisadores, o qual não dará as respostas prontas para os aprendizes, mas sim, formulará perguntas pertinentes que farão esses analisarem melhor o que estão fazendo ou como estão. Diante das Questões Auxiliares percebemos a reflexão dos estudantes por suas respostas: "...provavelmente seria um desafio pois ele não está tão pequeno..." - Nicolau percebendo que se a peça fosse muito pequena entraria com muita facilidade no orifício, "Será fácil, uma vez que as medidas estão um pouco menores que orifício" - Faraday constatando que sua peça ficou menor que o orifício, tornando o encaixe muito fácil.

$\mathrm{Na}$ apresentação do aluno, este fato também é observado:

Pesquisadora: Tu acha que se alguém tivesse feito ... uma peça com um triângulo de $2 \mathrm{~cm}$, por exemplo, bem menor, será que teria graça esse brinquedo aqui? Tipo, a peça se encaixaria no objetivo que tem o brinquedo?

Hércules: Ela iria começar a se encaixar na maioria das peças ali [aponta para o brinquedo, se referindo aos orifícios]

Pesquisadora: E dai?

Hércules: Não iria ter um desafio no brinquedo que tu tem que encaixar as peças certas no lugar.

Pesquisadora: Aham. E a tua peça, será que ela se encaixa em algum outro buraco? Outro orificio ali?

...

Hércules: Dependendo ela poderia entrar no quadrado também, eu acho. Se botar ela de lado. Só que dai não estaria na forma do quadrilátero. (Quis dizer que a peça não estaria no formato do orifício, ou seja, alerta sobre outra característica do brinquedo que cada peça tem seu lugar)

Quando se utiliza a impressão 3D no ensino, outras reflexões devem ser feitas para que a impressão aconteça com sucesso, como a posição da peça para a impressão, se ela necessita de suportes, se o projeto está num formato otimizado para não desperdiçar material de impressão e também tempo. Depois de lançar o problema analisado anteriormente, um dos pesquisadores questionou-os em relação à impressão da peça, assim, lançou-se a necessidade de uma reorganização dos pensamentos já 
formados, enriquecendo-os pela introdução de novas possibilidades não consideradas até então. A situação não deve ter como objetivo somente a construção de um artefato mas sim, um pensamento maior sobre a concepção do processo total, "a reflexão do que está sendo feito e os resultados obtidos" [BORGES e MENEZES 2018 p. 464].

Diante desta situação os participantes da pesquisa modificaram seus projetos iniciais, alegando que poderiam ter feito mais otimizados e que ainda respeitariam as demais características que o objeto precisa ter. A maioria dos alunos utilizou a mesma construção, mas retirou uma das faces, fazendo a peça vazada, outros fizeram um prisma vazado fazendo outro prisma por dentro (Figura 5). "Tirando os lados, tiramos o excesso de volume da nossa camada de espessura do triângulo onde usamos mais espaço no meu ponto de vista." - Albert relatando sua estratégia para otimizar a peça. Ptolomeu ainda descreve como sua peça deve estar posicionada para a impressão: "acredito que se for colocada de cabeça para baixo (com o teto como base) seja possivel não gastar nenhum filamento a mais", assim, não necessita de suportes no momento da impressão, não desperdiçando material de impressão.

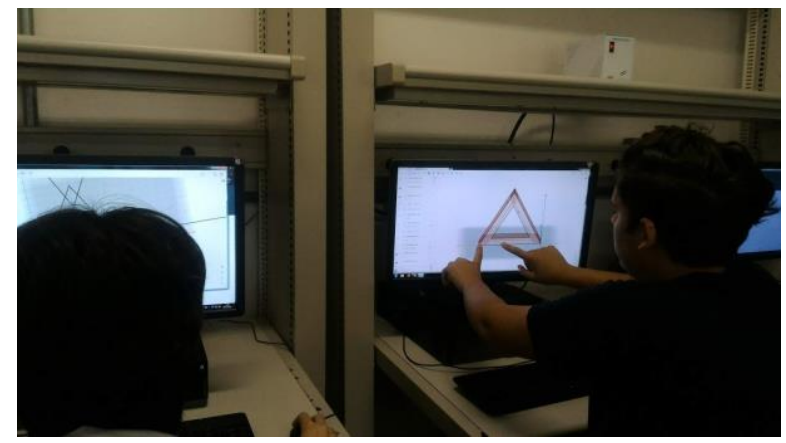

Figura 5. Aluno construindo sua peça vazada e discutindo com o colega

$\mathrm{Na}$ apresentação, a necessidade de uma posição correta para a impressão também é explicada pelo participante:

Ptolomeu: Eu acredito que tenha sim uma posição especifica que é como está aqui [mostra na tela] de cabeça para baixo, com a parte oca para cima, com o tampão para baixo, porque dai faz toda uma base para assim começar a subir as paredes, porque se eu começar a subir só as paredes na hora que eu for fazer o tampão eu acredito que ele vai afundar, por causa do peso do material, então eu acho que o jeito, eu não sei se funcionou, eu não testei, eu espero que funcione, de não desabar, assim as paredes, como elas vão ser feitas em camadas assim eu acredito que por essas linhas aqui [mostra as arestas laterais] uma vai sustentar a outra.

$\mathrm{Na}$ transcrição da entrevista ao que segue, percebe-se como uma situação problema faz os alunos analisarem diferentes estratégias:

Pesquisadora: Tu acha que daria para otimizar mais ainda, teria como tipo fazer ela...

Ptolomeu: Eu fiz, eu tinha sim pensando numa coisa, que era tirar esses pontos [mostra na tela os vértices] pra não usar filamento aqui, eu tinha pensando numa coisa mas eu acho que o geogebra não tem é deixar essas arestas finas.

Pesquisadora: Por que tu não tirou os pontos? 
VIII Congresso Brasileiro de Informática na Educação (CBIE 2019)

Anais do XXV Workshop de Informática na Escola (WIE 2019)

Ptolomeu: Pra eu poder explicar essa parte, eu acho que ficaria estranho. Mas eu não vi essa opção de por exemplo deixar estas arestas mais finas, deixa-la fininha, retinha, junto, no mesmo nivel do [mostra com o dedo a face]

Pesquisadora: Na mesma espessura que a parede.

Ptolomeu: Isso. Mas eu não achei essa opção, eu não consegui de jeito nenhum. Não sei se tem.

Quando os alunos são desafiados com uma situação problema, onde precisam criar suas estratégias de resolução, também é instigado a criativade desses alunos, nesta experiência os pesquisadores se surpreenderam com a originalidade das peças.

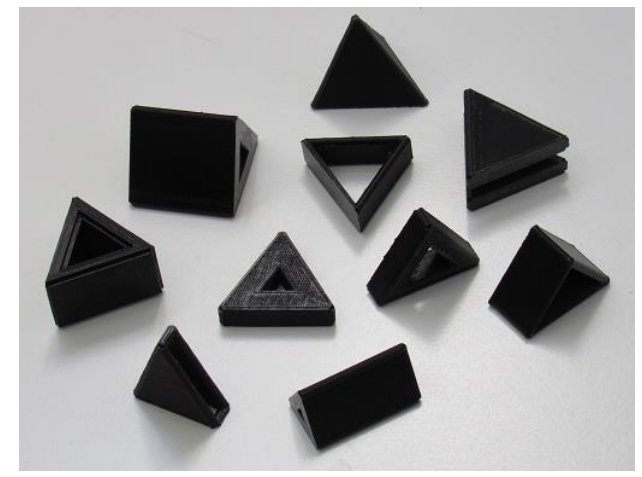

Figura 6. Peças construídas pelos participantes

Foi observado que nenhum dos estudantes fez a peça igual à peça original do brinquedo, eles não tiveram acesso a essa peça, assim, apresentaram um gama de diferentes resultados, como prismas triangulares, pirâmides, peças vazadas por uma das faces, ou com o orifício de outro prisma, ou ainda dois triângulos interligados por um cubo, essa gama de construções é mostrada na Figura 6.

\section{Considerações finais}

A experiência dos alunos com a impressão 3D permitiu sentir, analisar e julgar aspectos que a visão na tela do computador não permitiu, depois de impressa a peça, fizeram diversos julgamentos sobre sua construção. Foi interessante notar o enstusiamo deles, o deslumbramento do primeiro contato com a impressão 3D e ver uma peça projetada por eles ganhando forma física, sendo materializadas. Todos ficavam ansiosos em poder manusear suas peças, mesmo que não tenha ficado da maneira como imaginavam. Esses erros, muitas vezes de visualização espacial, de proporcionalidade, provocaram reflexões dos estudantes sobre suas estratégias, agregando experiências e conhecimentos. A inserção da impressão 3D no ensino de geometria não agrega somente mais um meio de representação, de visualização, mas também mais e novos raciocínios de práticas para executar e resolver um problema, um projeto.

A situação problema aqui analisada não só demostrou as possibilidades do uso das tecnologias na sala de aula, como também o uso da geometria dinâmica como ferramenta para interações entre sujeito e os objetos de estudos, ou seja, experiências onde os estudantes puderam desenvolver seus pensamentos e ainda a possibilidade de verificar a aplicação desses conceitos em objetos físicos, criados através de suas interações no mundo virtual. 
VIII Congresso Brasileiro de Informática na Educação (CBIE 2019)

Anais do XXV Workshop de Informática na Escola (WIE 2019)

Para os pesquisadores, a proposta apresentada serviu de inspiração para muitas outras alternativas com o uso dessas tecnologias visando o pensamento geométrico espacial dos estudantes de matemática.

\section{References}

BASSO, Marcus; NOTARE, Márcia Rodrigues. Pensar-com Tecnologias Digitais de Matemática Dinâmica. Renote, Porto Alegre, v. 13, n. 2, 2015.

BICER, Ali Bicer et al. Moving from STEM to STEAM: The Effects of Informal STEM Learning on Students' Creativity and Problem Solving Skills with 3D Printing. IEEE, 2017.

BORGES, Karen Selbach; MENEZES, Crediné Silva de. Uma arquitetura pedagógica para aprendizagem baseada na fabricação digital. In: Anais do XXiX Simpósio Brasileiro de Informática na Educação (SBIE). Fortaleza, 2018, p. 457-465

CANESSA, Enrique; FONDA, Carlo; ZENNARO, Marco. Low-cost 3D Printing for Science, Education \& Sustainable Development. ICTP-The Abdus Salam International Centre for Theoretical Physics. 2013.

HULEIHIL, M. 3D printing technology as innovative tool for math and geometry teaching applications. IOP Conf. Series: Materials Science and Engineering, 2017

JONES, Keith; MACKRELL, Kate; STEVENSON, Ian. Designing Digital Technologies and Learning Activities for Different Geometries. In: HOYLES, Celia; LAGRANGE, Jean-Baptiste (Eds). Mathematics Education and Technology-Rethinking the Terrain: The 17th ICMI Study. US: Springer, 2010. p. 47-59

KAPUT, Jim; HEGEDUS, Stephen; LESH, Richard. Technology Becoming Infrastructural in Mathematics Education. In: LESH, R.A; HAMILTON, E.; KAPUT, J. J. (Eds.). Foundations for the future in mathematics education. New Jersey: Lawrence Erlbaum Associates, 2007. p.173-191

LABORDE, Colette et al. Teaching and learning geometry with technology. In: Gutiérrez; A.; Boero, P. (ed). Handbook of Research on the Psychology of Mathematics Education. Sense Publishers, 2006. p. 275-297.

LIEBAN, Diego; BARRETO, Marina M.; REICHENBERGER, Sandra; LAVICZA, Zsolt; SCHNEIDER, Ruana M. Developing Mathematical and Technological Competencies of Students Through Remodeling Games and Puzzles. In: Conference Proceedings Bridges Stockholm 2018: Mathematics, Art, Music, Architecture, Education, Culture. p. 379-382

MONZON, Larissa Weyh; BASSO. Marcus Vinicius de Azevedo. Prospecção de Pesquisas sobre o uso de Tecnologias Digitais para o Desenvolvimento do Pensamento Geométrico Espacial. Renote, Porto Alegre, v. 16. n. 1, 2018

NOTARE, Márcia; BASSO, Marcus. Geometria Dinâmica 3D - novas perspectivas para o pensamento espacial. Renote, Porto Alegre, v. 14. n. 2, 2016

ZUFFI, Edna Maura; ONUCHIC, Lourdes de La Rosa. O ensino-aprendizagem de matemática através da Resolução de Problemas e os processos cognitivos superiores. Unión: Revista Iberoamericana de Educación Matematica, n. 11, p. 79-97, set. 2007. 